\title{
POLYCENTRIC CREATIVE COMMUNICATION: THE DISPOSITIVE
}

\author{
Algis MICKŪNAS* \\ Ohio University, College of Arts and Sciences, Department of Philosophy Ellis Hall, Room 202, \\ Athens, OH 45701, United States
}

Received 14 November 2017; accepted 15 November 2018

\begin{abstract}
The essay explicates the polycentric awareness as a ground of creative communication with anyone, anytime, to the extent that all communication is a sense making process about something. This makes accessible "Others" from other times, present in texts which open communication through linguistic and cultural media. We read Plato and argue with him about justice, or debate the issue of beginning of the universe with astronomers. These two levels, polycentric and dialogical, is supplemented by a concrete analyses of body as an active and interactive dimension with many contemporary technical media, from film, television, Internet, and smart phones.
\end{abstract}

Keywords: communication, creativity, media, bodyness, interactivity, Others.

\section{Introduction}

Before any clear understanding can be gained concerning the current proliferation of the term "dispositive", it is necessary to show the problematic in whose context such a term could make sense. The first issue, that still predominates the discussions of this term, appears in the preunderstanding of representation in contrast to presentation. This issue appears not only in mass media, but also in such theoretical concerns as are offered by deconstructionists and postmodernists. Claims are made that the Western tradition assumed logocentric position based on presence of the given. The effort, then, is to argue that there is no presence; if this is granted, then there is no representation and thus, by extension, no misrepresentation. One cannot claim that some minorities, or some gender were misrepresented - after all, they were never present. We shall return to this issue after discussing the origin of the rise of representation. The latter is a result of modern metaphysical speculations in contrast to the classical traditions that had conceived of the world as unavoidably given - present. A theory - theorea - dealt with the presence of some reality, some being. The condition for this presence is the mode of thinking wherein all the things, events, social customs, cultural designs were regarded from a limit - peras. If one

*Corresponding author. E-mails: mickunaa@ohio.edu; amuali@gmail.com 
can delimit the limits of something, if one can decipher the boundaries of events and things, then one has their presence. One of the ways of speaking about presence as seen from the limit is essence. Theorea is a way of capturing this essence, indeed, theorea is an embodiment of the essence by other means. This is to say, theorea does not represent the given; it is the very presence of the given. The difference between the two - presentation and representation - is also the difference in the notion of creativity.

\section{The present and the mediated}

The argument for the presence - and its expression as essence, is restricted where even the kirios on, the most revered, is seen from the limit, even if the limit is nothing. In principle, Classicism saw all from a limit, and hence could create both material forms and formal precisions. The latter too were discovered as given. Even the unlimited, the apeiron - was compelled to emerge in some form, in a given parameter. If one regards Platonism, one notes immediately that the "ideas" as reality par excellence, comprise absolute limits, forms, to the chaotic flux, to the multiplicity of givens (Plato, 2010). Indeed, the latter must respect the limits of the forms in order to be. Even if one regards Aristotelian naturalism, with its seemingly unconstructed dynamis, one also notes that the dynamis is given only in a specific substantial form, comprising a limit (Aristotle, 2008). Even in an extreme interpretation, where the dynamis may be regarded as completely formless "process", one discovers it to have a telos which contains all the forms and toward which the dynamis unfolds and thus obtains its limits dictated by the "thoughts" in the final cause. In brief, whether one regards the two extremes, Platonic "idealism" or Aristotelian "naturalism", as expressions of Classicism, one finds an unavoidable presence provided by a limit and its hermeneutical diversity. In principle, presence does not require representation to the extent that all things, indeed being itself, the entire cosmos, is accessible and understandable within limits. Greek creativity was classical, within recognizable forms, and thus classical. They created "ideal" classical figures to which humans hat to aspire in their own life. Even the creation of the essence of society had to be ideal in which people had to aim at "beautiful" behavior. Given this context, representation could not be a serious issue and resultantly neither deconstruction nor postmodernity could make sense in the classical context.

It is quite otherwise with modern thinking. The given is not directly present. The ground of this rests in a unique honoring of being: in order to be regarded as most worthy, being was conceived to be positively infinite and, to lend glory and power to this infinity, it had to be regarded as a creator of an infinite world - not unlimited, but positively infinite world. This radical reconceptualization provides a series of implications. First, it is in principle impossible to have a presence of infinity, to contain it within a theory. No articulation of events - one after another or in sum could make infinity present. Resultantly, one must have representations that, regardless of their extent, cannot offer the presence of the universe. Second, if the universe is regarded to be infinite, then any point one picks can be deemed its center. Every calculation from a chosen center will be correct, but not a presence of the universe. In this sense, we may have many and sundry representations, none of which, and neither their sum, are adequate to give the presence of the universe. This shift toward a selection of 
any possible point as a center is the source of the Copernican Revolution, and a possibility of creative construction of multiple theories. Third, every chosen point comprises a specific perspective. The latter, as positional, represents the positions of others and itself only because it cannot present the universe. Any shift of perspective, recreates other perspectives in novel ways. Fourth, given such a position the perspective is all there is of the universe. After all, one cannot find a universe, specifically if it is infinite, and then take a perspective to it. In this sense, perspective means the very world one has, and the latter is created and constantly recreated. One cannot leave the world, and then take a perspective to it. If perspective is a representation, then the representation is all that one has as a world. Fifth, this notion of perspectivity has been extended to the conception of world view. There may be a scientific world view, a theological one, a metaphysical, ontological, ethical, and even aesthetic world views. None allow for presence of the cosmos, and hence each is a created representation wherein the latter is the very world one lives. Yet it must not be assumed that somehow the sum of the world views would offer us the presence of an infinite cosmos. This is excluded on two counts: first, a finite enumeration of world views will not make the infinite universe present; second, each world view, as positional, locates itself by representing other positions as different, and hence through the difference represents its own position. Yet each position will read the positions of others precisely as the position requires.

There is hardly a need to extend our analyses of these representational-positional multiplicities into their various modifications, such as Louis Althusser's multiple discourses, each reading all other discourses in terms of a specific one, i.e. representing them precisely as a given discourse requires (2005). The same can be said of philosophical hermeneutics, wherein a philosophical thesis will represent all other theses in terms of its own logic or a frame of interpretation. What is relevant in principle is the understanding that representations do not offer a presence of the world, but mutual differentiation of finite positionalities, with an open horizon of possibilities to create other positions. Finite, because there is no infinite positionality in principle, i.e. a priori impossible and hence a creation of other positions is left open. Representation cannot offer the position of other representations without regarding them from its own position. Thus the notion that some position misrepresents other positions loses its relevance. But this suggests that misrepresentation also falls by wayside. Jean Baudrillard's simulacrum becomes redundant (1983). It still pretends to uphold a world that is no longer available. The same can be suggested of Jürgen Habermas' notion concerning epistemic claims as dependent on a position of interest (1968). Any theory that claims to have a truth function due to "facts", is comprehensible if the interest position is understood. Equally relevant would be the claims of "discursive" practice theorists, including Martin Heidegger's notion that every discourse reads all other discourses in terms of a preunderstanding of a given tradition (1962). Even philosophical hermeneutics confirms this: any theoretical position interprets other positions in terms of its own frame and, indeed, cannot help but do that.

\section{Mediations}

The battle concerning the "unmediated mediation" takes the following forms. If one deems awareness to be the ground of all world understanding, i.e. as the founding or unmediated 
medium, one must speak and hence discover that one's awareness is mediated, and necessarily so by a polycentric field which includes not only the "sense" of oneself, but also of other subjects. Modern Western subject was born with the positing of material-mechanistic universe and with it a mind that contains thoughts, sensations and feelings which do not exist in the "objective" universe. Yet it is also the case that the subject or, more broadly, the Self, is always given as the background of all theoretical postulates and hence seems to be the final medium. Yet a question that immediately arises is that of the subject or, more broadly, Self and Other. After all, communication is with the Other, under the assumption that we are not some entity encased in our subjective interiority - solipsistic - inaccessible to the Other - as would be the case with Cartesian solipsism and basic empiricism. And yet the very awareness of Self makes sense only in its difference from and correlation to the Other. If our concern is with the modern Western notion of an Ego then, at this level of awareness, it is glimpsed immediately as a reflected Self. After all, even René Descartes (1985) requires a Self which, while reflecting, assumes an Ego different from the reflecting Self - the Ego is already the Other. Thus, the Self is always mediated by the Other, forming an awareness which can be extended through numerous others showing the limits of the Self, its difference from Others and yet an extension of its awareness through the different Others. The Ego marks a distance between the broader Self and its Other, posited in modern philosophies as Ego. In their static identifiability, the latter refer to the flux enacted by the Self, and exhibits a characteristic that is different and exclusive of the Self. This suggests that the Self cannot be exhausted by an identifiable act that is symbolized as an Ego. And yet the Ego is present as a reflected Self prior to an act of reflection. The Self recognizes in the Ego one of its possible acts. The sense of the Ego is the notion of Other, different from the Self.

The world is experienced in a polycentric way, where the Self is not only aware of something, but is aware of its limitation and expansion through the awareness of Others - thus an open horizon that is the very depth of both social interaction and history. The singular being, with her perspective regards herself as all encompassing: this is the way that the whole universe looks. Yet encountered Others have a different perspective, providing a reflective moment to see her own limitations and also to position herself "from there" as another intentionality. The Other shows both her limitations and at the same time opens her to more than her own intentionality had allowed. She sees with the Other's vision. The entire modern pedagogical system is founded on the notion that we access the understanding of the world by "borrowing" the perceptions of others (we stand on the shoulders of giants). The borrowing and, in principle, extension of one's own awareness of... includes the Others whose awareness of... are inscribed in texts, in libraries, in archives, and in stories, in pedagogy, and in daily discourses. One sees with the theory of Isaac Newton (2010), Max Planck (1969), Aristotle (2008), with the intentional orientation of Thomas Mann (1995), Leo Tolstoy (1994), Fyodor Dostoevsky (2002) with The Brothers Karamazov (in Russian: Brat'ya Karamazovy, first edition in 1879-1880), Bhagavad Gita (2007, in Sanskrit: bhagavad-gìtā), Electra (Sophocles, 2008, in Greek: Elektra), the Bible, and Friedrich Nietzsche (1974). One forms a polycentric awareness whose presence is not yet temporalized, yet whose field is continuously extending, leading to an all-encompassing regard that the universe is accessible to the sum of all possible perspectives or intentionalities. Such a task is infinite, and it 
is present poly-centrically to every perspective. Yet it is to be emphasized that it is not yet historical memory, but an extension of awareness through Others that subsequently can be interpreted as memory, historical past and tradition. Awareness constitutes itself in an inter reflectivity between positional egos and between its own intentional perspectivity. All this is most relevant to understand the variety of contemporary media, disclosing the presence of Others and the Self. This context of extension is the fertile ground for all creativity which includes a recreation of our own perceptions and, by reflection, a creative reinterpretation of other texts. In this sense, there is no end to creativity, since there is no final text.

The polycentric "history" is a directionless horizon wherein the present, past and future have no specific locations. One can take a temporal dimension from Renaissance texts and make that the dimension from which past and future horizons will overlap; one can search for the best constitutional defense in texts and find those texts stating what one is to do tomorrow - overlapping of time awareness; or one can take a geocentric perspective and with all the technical apparatus wait for light waves to come from the past, wherein past-presentfuture overlap, where present, expecting something from the future meets the past. What is important is that without ontologization of time, history has no direction, and indeed no specific temporal location - as awareness, nor does it have anything to do with spatial metaphor of inner and outer. As if historical awareness were an entity that goes through stages and can be "found" somewhere or sometime. Texts in libraries are signifying intentionalities that depict the world in accord with different awareness modalities. Only after we are aware of the ways of explicating the world, can we then check for the age of the paper, the hide, the stone, but even that will turn out to be "intentional", i.e. the hide will reveal not its empirical presence but its "age" and therefore will be seen primarily as conscious phenomenon. One aspect remains to be disclosed. The polycentric history, does not offer some sort of final or ultimate unity, since the latter would be another perspective. Besides, no polycentric horizon can exhaust the awareness of the possibility of not yet available Others by any perspective.

Second aspect is the linguistic mediation deemed to be the unmediated medium. The latter is the ground of polylogical "dialogue". The arguments, presented so far, do not deny the presence of language in communication; following the polycentric field of awareness, such a language is polylogical. Polylogue is an extension of dialogue. To speak is to speak to someone about something, some topic, issue, value, religion, scientific theory, and thus, at the outset, to be a dialogical partner. But we also know that as we perceive with the perceptions of Others who limit and extend our awareness, we also extend out dialogical engagement into polylogical horizons. Without mentioning an author, I can say that gravity is now considered one among other forces in physics, but it also means that my dialogue is already polylogical and includes Newton as a copresence. We might even have our favorite polylogical partners across vast atemporal horizons. Any question I confront, I always consult the gigantic dialogues between Plato, Aristotle, the Arabic "doctors" and mix in the barefooted Socrates. After all, he defended philosophy to the death and became an example what it is to be dialogical and polylogical.

Fortunately, I can engage in such a polylogue, because language is the bearer of the way the others' intentions "meant" events, disclosed issues, and the world that can never be doubted. At the outset it must be emphasized that dialogical world is intersubjective and is 
one major way of resolving the protracted controversy between the proponents of the priority of individual over society and those who claim the supremacy of society. In the first instance, society is regarded as a sum of separate and indeed solipsistic individuals having solely antagonistic relationships, while in the second, the individual is a conjunction of social, events wherein society (at times interpreted in the form of institutions) is the defining dimension. Meanwhile, the composition of dialogue has to be understood as prior to and foundation of individualism and social holism. First, in dialogue the Other is not present as an object, a given entity, a mind inhabiting a body, but as a copresence engaged in a common venture. One speaks with someone about something, some topic, concern, subject matter, prior to regarding the other as a subject or an object. The commonality, here, is a subject matter in which WE are engaged, which WE confront, dispute, or agree upon. There is granted an orientation toward something with an orientation of a Self to the Other.

Second, the notion of sender-message-receiver must be modified away from a sequence of activity-passivity, where the sender acts, while the receiver accepts the message. Rather, it is a complex process of the establishment of both sender and receiver in a way that they both are contemporaneously active-passive as a mutual articulation and interrogation of a subject matter. Each partner founds the dialogue and in turn is founded by it. There is neither the priority of the individual, as the ultimate foundation, nor of the dialogical WE as the more encompassing. They are mutual and can be regarded analogously to a melody: each note is an individual and without it there would be no melody, but the melody also allows a note to have its say as position in the melody. Change in either one is mutually change in the other.

Third, the dialogical partner is not merely the currently co-present other, but the others whose orientations toward the world, their perceptions of the topic, the subject matter, are equally co-present. The books I read, the conversations I had with others - perhaps long forgotten - comprise an extension of my perceptions and constitute a polycentric dialogical field. I perceive with the perceptions of the others, perceptions that contest, extend, and modify my own regard of a given subject matter. The same is true of my current dialogical partner; she too is founding of and founded by a polycentric field, and in our dialogue we mutually involve our polycentric awareness and hence extend our polycentric participation. This also constitutes the basis for transcendence of one's own limitations and resultantly for openness and freedom. Without the other, and without our being co-present in a polycentric field, we would lack the transcending movement.

Fourth, polycentric polylogue defies the traditional notions of sequential history; polylogue constitutes a field of temporal depth wherein the "past" partners are not passive, but participate equally in articulating, challenging, and interrogating a specific issue, topic, or subject matter. Thus, it is quite normal to say, for example, that for the Egyptians humans were not categorized in terms of some presumed racial features, but in accordance with hierarchies of social positions and tasks. Of course, the focus of our polylogue is the human, while the others, the Egyptians, open and extend our perception by showing our own limitations and positionality. Here, their perceptions contest actively our own perceptions. At the polylogical level we are constantly decentered from our limitations even when we would reject the others perceptions of a given subject matter. Indeed, the very preoccupation with rejection, the efforts to demonstrate the inadequacy, the mistaken understanding, and downright error, shows the extraordinary credence and co-presence of the other. 
Fifth, the polylogical co-presence of the other not only decenters mutually absolute positionalities, but also constitutes the initial awareness of human situatedness as well as a reflective self-identification each through the other. It could be argued that polylogical field comprises the domain of inter-positional reflexivity such that one recognizes oneself only due to the difference from the other in modes of awareness of a subject matter. This is the transparency principle: I know myself to the extent that I reflect from the other, from the how she articulates a specific theme. I see myself through the different perceptions offered by the other that connect us by way of a common theme, task, subject matter, and allows us our recognition of our own positions. Another aspect of this morphology must be mentioned in order to avoid misunderstandings inherent in the efforts to objectify the other. Even if we engage in a dialogue about the other, we shall find that she cannot be understood apart from her perceptions of something, of some concerns inherent in her world. We shall understand her only to the extent that she is engaged in some task or concern, and thus is an aspect of our own polycentric field. After all, to discuss Virginia Woolf, is to discuss her views about something and thus introduce her as our polylogical partner. Even if we were so crude as to intrude into her "private feelings" we would still understand them as "feelings about something". She, as well as we, are comprehensible only with respect to the world we address, contest, and share in our different ways.

\section{Media and body}

The level of polycentric awareness and polylogical communication we explicated is present concretely at the level of bodily activity which offers depth to the two dimensional awareness through texts and dialogue. Watching mass media, television, film, computers, we are present to a two dimensional phenomena, although we take for granted that what we experience are full bodied, three and even multidimensional world. Thus, to understand this media dimensionality we must understand the way body is co-present in any communication. The introduction of bodily presence require a minimal comprehension of the structuration of body in action, body as individual, and body as social. The investigations into the configurations of the dispositive cannot be understood seriously on the basis of a body sitting in front of a television while the mind, as an added attraction, decodes and interprets the images. Moreover, this sort of understanding does not account for the body that is regarded as an individual and as socially interactive. This is to say, the traditional depictions of body as bio-chemical, as physiological, as psychosomatic give us anonymous, universal body whose description can subsume all bodies. Contrary to this, we must explicate the practical body that lives its orientations, activities, faces its tasks and is engaged with others in ventures grasped in direct action and interaction. How could one watch a film, a television program, or a video and not understand, indeed not be corporeally present, to the activities performed. Our task, then, is to delimit this body in action and its incorporation in perceptual-perceived body events. The incorporation, the coupling or the linkage to contemporary mass-media requires such understanding. Such understanding must fulfill the following requirements: First, body must possess a generality of activity that is not an expression or an embodiment of an ideal, but neither reduced to brute facticity. Second, it must constitute active self reflectivity as a tacit 
recognition of "what I can do". Third, it must be coextensive with and differentiated from the activities of others, allowing one to say "I can do that" or "I cannot do that". In watching some performances, we recognize that indeed, we can jump, but not as high as the athlete, we can fight, but not as brutally as those bastards in wrestling rings. What we recognize, in brief, is a body comprising an entire system of performances, of abilities that are sufficiently general to be performed by others, but not in precisely the same way. Fourth, the active body as expressive and "ethical". By the latter term we do not mean a set of norms, but a way of bodily being with others. A turning away from someone in need speaks its own language, holding someone in grief tells its own story; indeed, such actions may compact numerous stories, but we contend that all of them speak of our expressive relationships to others, speak of our ethos. This body that we are is the one that participates completely in everything that we perceive in mass media. Finally, fifth, a synesthetic body such that one perceptual field, such as vision, translates directly into other fields, such as hearing, touch, emotion, images, memories, and expectations. The following brief section offers an analysis of this lived body as it pertains to participation in mass media.

In this context, we shall not use the obsolete notions of communication as transmission of information, as dependent on cultural codes, and as secondary level reality that attempts to represent something. Rather, we shall move toward corporeal perception, participation, and intra-communication. Thus we hope to obtain a unity among differentiations of information, media, and understanding-comportment. At the social level, the modes of awareness will be regarded as inter-corporeal and not just as observers of some images, discourses, present in media texts. If we regard communication as an operation linking minimally two systems which constantly reshuffle the informational content, then we could say that numerous such systems constitute a complex differential process that has to be organized at another level, and done in a simpler way. This is accomplished by extended communicative process that follows technical media structures capable of transforming sequences and absences into presences, and drawing the "viewer-listener" into direct participation. Thus print, photography, film, television, etc. each begin to duplicate and proliferate copies that link numerous populations. While mass printing performed this function initially, such function, as we shall see, required imaginary participation. With radio, film, television and most recently, Internet, smart phones there is an increasing concretion of participation and simplified communicative organization of linking, specifically temporal and spatial events irrespective of their geographic or historical positions. This becomes the window to an open domain of public exchange of opinions - at least in principle if not always in practice, and also changes structures of space and time and selectivity of relevance. Relevance may mean selectivity and coordination of themes and their immediate copying around the world society - with, of course, a very strong side effect of creating short term memories. The major reason, to be seen in greater detail subsequently, is the synchronic structure of the current media, such as television, Internet, smart phones. Allowing the linking of events to awareness without a distance. Thus, the very quality of awareness undergoes a radical, creative transformation.

Each dynamic extension of the awareness of the others, the extension of our polycentric horizon of awareness, carries an essential element of temporality. The reduction of communicative complexities through global selectivity of themes and connections became a neces- 
sity. Economic news - a theme that connects and involves the globe and us. Even without a specific thematic content, the possibility of encountering others from everywhere, has its own fascination, specifically with the central possibility to insert oneself any time in this linkage, to be at the scene, and thus to be open to the world horizons through others, such that these horizons are more preeminently our reality than the horizons of the being with others of daily awareness. One can even claim that the linkages to the mass media are maintained not because of the information, but because our perceptions are completely intertwined with them. The millions who watched the first two steps on the moon certainly did not receive a rich content of information, yet were present at a world event at the same time, the various current events are known immediately. This is to say, it is not the cultural or informational quality that are at issue but the very relevance of our participation in events. The participation is, of course, mass mediated proliferation of copies that circle the globe. But the copies, giving us perspectives, is all we need for our current reality.

Whatever technology may be, what is relevant for our current deliberations is the level of technology that pertains to mass reproduction of the texts, perspectives and images such that there occurs a change in the ways of participating in such media. This change occurs in the fact of the absence of the original. In this sense, and as noted above, there is no original presence, and hence no representation; there is a mass proliferation of "copies" without the original. Techniques of reproduction remove the copy from any context, given facticity, its world. This also indicates that there is no privileged access - by some elite - to the once lauded "original". Even in arts, Mona Lisa (1503), Clint Eastwood, Charles Manson and Ludwig van Beethoven appear on placards, adds, tee shirts, toilet paper, magazine covers, and interwoven in digitalized caricatures. The viewer can either pass them by with a casual glance, or engage in casual shopping among them. Perhaps it could be said that such mass-mediating production is super mallization of images found in Maxima and many other complexes; mallization does not respect any original or its space-time of origin. Here even the cherished metaphysics of authenticity, in the sense of historical origin, becomes redundant, and redundant becomes the notion of authorship. While the photograph, the cinema, the video and television have different modes of "audience" participation, they are indefinitely reproducible and present to "the people". It is also to be noted that the definition of audience will have to be reevaluated. The lack of specific space-time, the synchronization, either blocks or abolishes the notion of authentication and the questions of socio-economic and ideological conditions of such series of copies. The boundaries between genuine and fraudulent, ethical or unethical, lose their value and indeed place into question any social authority that may still want to legitimate such distinctions. Examples abound in some documentaries showing the inferiority of the others to Anglo-Europeans via enlargement, slow-motion, and selectivity, creating a reality that legitimates the claims of mass media to be representation of truth.

It is a curious historical occurrence when the emergence of movies, as proliferation of multiple copies occurred, there was an effort to frame them in "theatres" with "classical" architectural styles, as if to block the death of the original and authentic. This effort "against the lower classes" wanted to lend copies a frame of authentic reality, a presence. It is as if to say, the masses will be elevated to a higher aesthetic truth, inaccessible to them by any other means. The movies, as "theatre" could not be placed in "low life" structures of housing. Thus 
the illusion of placing movies in structures having Greco-Roman and Romantic airs. Was this an effort of the bourgeoise ideology to maintain a class position, even if the film medium was defying such a position? What is at issue, in this context, appears to be the ideological effort to maintain a bourgeois "authentic history", in face of a medium that, when presented in the theatres, has no history. Thus, the selection of architectural styles of antiquity - to extend the claim to legitimation - is prevalent. We shall call this effort as permanence enhancement, in face of the emergence of total flux that has no fixed points of reference and hence every point may become, and indeed has become synchronous. The new filmic medium was, for a period, given an atmosphere of authenticity - but to no avail. After all, the current mass media - televisual, video, etc. - are present in every mobile home. As a copy of copies, the film is removed from any history, and acts as a self-reflective substitute of itself, thus constituting an audience that cannot claim to have any authentic experience. These paradoxes could not be resolved; if one pretends that the grand palaces of movie theatres are extolling the permanence of high culture, what one shows within these palaces - the life of poor immigrants - defies the high culture. If one shows the Hollywood glamour films, dealing with high society, one exposes such society to multitude of copies and inauthenticity. At least, in a promissory way, "everybody can live this way". Indeed, film, in many cases, comprised a mass medium that ridiculed the high society. Obviously, the copies of copies, were also continuous with consumerism, and thus all the high styles could be copied on the street. The glamorous style was as near as the shelves of cosmetics at department stores. We have here not only technological change, but also the public's mode of awareness. The audience no longer travels to Hollywood for glamor; Hollywood is a given in the theatre next door. The theatre overcomes "reality" by making the copy a reality. As we shall see subsequently, there will be no other reality. The authority of the authentic "objectivity" becomes another copy on the newsreel. Regardless of economic status the proliferation of copies ushers an audio-visual equality at the level of perception. Each view, each perspective is open to all, and all at once.

Whoever is mass-mediated, is exposed to numerous and, until recently, anonymous viewers who could be exchanged equivalently - without a loss. Each viewer, reader, listener, is coupled with a power of judgment on which the extent of the proliferation of the copies will depend. The quantification of audiences is a result of this massification of the copies and hence judgments of their "quality". We could even surmise that "cultural criticism" has its origin in this context. We are not concerned whether the copies of copies became institutionalized, whether they led or did not lead to political action instead of remaining mere entertainment for the masses, or whether they were propelled by, or themselves launched some economic forces; we are concerned with the very phenomena of mass-mediation that, in a final analysis, comprises various forms of the dispositive. The extrication of these phenomena, inclusive of their extrication from private, sacral, high cultural loci may lead, and more likely has led to their restructuring as public and hence political; but this does not mean that they have originated the political. Yet on the other hand, they concretized the political by giving it a tangible mass face. A film, even photography, can be duplicated without a loss and thus accessible for anyone. The faces of stars, as well as scoundrels, are flashed by photographic copies, as well as by filmic, televisual, and video means "everywhere" and "at once". The images are shown not to be "seen through" as signifiers toward the signified, 
but as given in themselves, events and realities as they are seen, but both as a perspective and from a perspective. The "from" is the camera's position which becomes regarded as the position of the audience, and the perspective is the reflexive positioning of the entity in the mass-mediated material.

The positioning is discontinuous and requires recoupling. One scene, then the next one comprised of different events, then the hero enters this new scene, and has to be reconnected either verbally or through gestures in the scene with the other scenes. We shall speak of this phenomenon as inter-reflexivity wherein various gestures and discourses reflect one upon the others and equally reflect the audience such that the latter has, to speak minimally, a position. This complex phenomenon of inter-reflexivity will be articulated subsequently. What is at the outset important is the removal of the audience from immediate participation and the perception of participation. Thus the great revolutionary heroes, losing their struggles against "authorities", draw the revolutionary masses to gaze upon "the events" as given before its eyes. Here, the revolutionary awareness is one of looking but not acting. But then we can also suggest that there is a reverse coupling, and reverse reflexivity whereby production of copies of mass mediated events, constitutes those events as equally copies - theories about mass mediated copies, philosophical debates about such theories, the objects to which the latter two wish to refer, are all proliferated copies. Any self-reflection and even self-criticism, is another copy in a world of pop-cultural critical studies. They too are commodified, perspectivised and publicized. If there were innocent hopes for the new technology, such as making the world accessible to critical evaluation and resultant correctives, it had to vanish with the constitution of reflexive logic of inclusion of the perceptions and perspectival positions into the very proliferation of copies after copies. We can sit in an ambulance or a taxi while remaining in the kitchen and watch the hilarious as well as the tragic come into our lives.

It has been contended that at the level of awareness, mass media, even as print, begins to break down the Euclidean notion of space. In reading about the events, we are aware of such events in a signitive fashion. We know what they mean, we understand them from the perspectives of others and are capable of filling either imaginatively or by memory the empty significations, the meant objects. It is our body positionality, our imaginations, memories, indeed the horizons that offer perceptual content. But with the gradual shift toward other media, such as radio, the perceptual filling thickens; we hear the other in our room, we hear her audial expressivity, we hear her laughter and - synesthetically - hear her smile and her expressive face. If we extend the technical media, say toward film, we thicken the perceptual presence of the other and - more importantly - I am bodily located as "here" in contrast to the other's visible bodily "there". Indeed, the film, television and smart phone media allow me to see events, vistas, facades of buildings from all perspectives. I can fill in his body position where he holds the camera and hence see the way he sees. In addition, the others who confront him, also offer positions and thus other perspectives. What we have is a shifting multitude of bodily perspectives, each representing, positioning, and differentiating from one another. I can attune to their body performances and can enter the concrete vectors of their gestures, extended and varied by speech; I can see the angry, pensive, cold expressions across their faces and hear these expressions in their voices and total body comportments. Although the movie theater is designed to make us sit, or the television might allow us to lay 
on a couch, they are also designed to draw us into the action - to fill in the body positions of the others, the actors not imaginatively or memorially, but by virtue of the "real bodies" on the screen. Obviously, we too are given a perspective of the invisible position of the camera. The latter, nonetheless, shifts to show what the others see, positions the others' visions, and allows me to see from their positions. This is a peculiar phenomenon of reversal: I am here, and yet I see from there of their positions. I see from where they see. What is most important is the constitution of synchronicity. While I am watching "from here" and "now" I am given the perspective of the other synchronously. In this sense it is not an anonymous transpositional, universal logos, but as it positions itself it positions both the audience and the actors as bodies synchronously. The latter allows corporeal self reflection, i.e. the constitution of oneself as a subject here, and as an object-subject there. We say "object-subject" because we see the other body, but the latter comprises - by way of camera angle and movement - our own seeing. We are suggesting that the new technologies, relevant for the understanding of mass media and the dispositive phenomenon, constitutive synchronicity.

Even with the filmic or television media, there is no presence of "reality"; rather, the shifting body perspectives constitute whatever the momentary focus of the perspective and/ or perspectives happens to be. If there is still a language of "reality". it can only mean a momentary confluence of various perspectives, body orientations. Some may call this confluence "aperspectival", or seeing something "from everywhere", but these designations still depend on some permanent spatial object. In the filmic depictions, the object is rarely a thing, and what we get are facades of numerous things, none of which are given "from everywhere". More likely the "focus" will be action and interaction, requiring at least some kinetic activities of the audiences: eye, head movements, attention, audial attunement, and even synesthetic "translation" from one to other sensorial registers. Although the filmic screen actors may be presenting some fictional characters, they, nonetheless, are on the way from diachronic toward synchronic time. Whenever the events may occur, for the audience, the actions on the screen are present in "flesh". Indeed, the space of the filmic action stretches right before the audience, and the latter is incorporated in that space, but not a homogeneous space faced by a homogeneous, encompassing subject.

Perhaps such a subject was still available in print medium but in the filmic, and as we shall see, in the televisual and electronic media, such a subject is restructured by facades, shifting actions, and momentary foci. While the interplay of perspectival facades was marginal in the print media, since the latter had a narrative style, in the new technologies, the play of facades - reaching all the way to play of images - takes a central position. To use some of the current jargon, the center does not hold, and hence the marginalized become an all pervasive style in open, public communication. We could argue that this play and interplay comprises the dramaturgical character of filmic, and above all of televisual and electronic mass-media. This dramaturgical aspect is more important than the "informative" and ideological discourses. Indeed, the very dramaturgical interplay hardly needs language; the latter begins to play a subordinate role. At the filmic level we acquire a corporeal subject and subject-object corporeity as a phenomenon of a synchronic technosphere. The latter is all-pervasive and the economic system that dominates this pervasion is empowered to be global. Here, the classical modernity, still seeking to lend itself an aura of some permanence, 
is finally dethroned from progress and history toward synchronic time. The presence of the encompassing technocratic impact overcomes the past and the future with direct desire to inhabit, participate in, and possess the mass mediated facades. This is to say, the tapes, the videocassettes, video cameras, personal computers, enclose the person in their own world. This system embodies the observer/participant in a decentered space and synchronic time in an initially seeming disembodied space, where any reference is intertextuality.

The new technologies, which we called synchronic, constitute as well a recoupling processes that transform a reading culture into a audio-visual-kinetic culture. The direction of society as purposive system of self-reproduction can no longer depend on some ideological supra text for synchronisation. Rather, it depends more on the expressive-aesthetic synchronisation of gestural bodies as a language of kinetic audio-visuality. The electronic management of social interaction replaces decisionistic consciousness powers by software as recoupling processes, where the interplay of images, sounds, graphs, move from marginality to centrality. Here the language of expressivity, representing nothing, couples to the direct expressivity of the bodies of the participating audiences as if to impact the latter directly. It is to be noted that the language of "unconscious" stimulation also becomes redundant. After all, the recoupling is not only that we attach ourselves to the media, but it attaches itself to us through our expressive gestures and thus sends us to pretend that what we obtain from the mass media are the fulfillments of some unconscious desire. We contend that the recoupling is made possible by an incessant reproduction of all the audio-images and expressivities across all media, inclusive of the capital that is invested to grease the skids of this reproduction. This is to say, the value of capital depends on the reproduction of the images and their coupling with the audience, and the latter's recoupling with the audio-images and corporeal gestures. This is proven over and over again in such banal situations as political campaigns. In order to engage in campaigns, one must invest money in the reproduction of copies; the reproduction of copies will bring in money. This is to say, the images must be capitalized. To speak in accordance with another theory, the semiotization of star images is capitalization, and capitalization of star images is semiotization. It is no accident that the most popular recent president was an actor and chose the recoupling technical process, allowing him easier capitalization of images. What could be suggested that the public elects a person with whose politics the public would disagree and rejects a person with whose politics it would agree. The circulation of facades, perspectives, fragments that are coupled together, and recoupled with the audience, is the first novelty of synchronic techniques; the second consists of the audio-visual kinesthetic pervasion of expressive bodies, and the third may be the cybernetically directed recoupling of the two former with the addressed and engaged audience.

While Jean-François Lyotard's (1984) analyses of the technologization emphasizes the problematic of epistemic access to the world, what we are showing, as the context for the dispositive, if not dispenses, at least diminishes such epistemic focus. Here we have to do not only with participatory corporeity that is recoupled to the media by the cybernetic management and circulation of perspectives and facades, but also with the facticity that the world of "images" begins to be the sole world of postmodernity. This is to say, the shift from modern episteme to the synchronic technologies and recoupling processes is not a shift to a new episteme. The latter term has no resemblance to the already functioning dispositive. Where 
the electronic recoupling techniques shift decision mechanisms from subject to software, the question of who knows what is redundant. Programs decide what images can be synchronized with emotive effectivity and kinesthetic expressivity - and before the audience can make a judgement, the recoupling has accomplished its task. The principle of synchronization technologies, inclusive of recoupling processes of such technologies, are completely bound up with the audio-visual and kinesthetic sense of the body of the audience. There is no distance, there are no images of..., representations of...; there are events that have no signitive function to some "reality beyond". This we say without a blush; the world is, after all said and done, a world of space and time and motion. But the synchronistic technology transforms the modern three dimensional space and sequential time, a space of locations and distances, into presences without distances, into the given with which we interact "right at home". The space of concentrated metropolitan places of business, of commerce, of trade and transportation, is dispersed and yet made more accessible. The times are at an instant from every time. This is to say, space, time and motion have assumed radical transformations. Even the traditional distinction between audial and visual spaces has been subtended by expressive-kinetic and recoupling spaces that offer the directness of events. "Watch what happens to my counterparts headquarters" announces general Schwarzkopf during the desert storm briefing of mass media. After all, he did not say "watch the images of events 100 miles away".

\section{Conclusions}

Emphasis must be placed on active body as interactive with mass media and as a field of inter-corporeal awareness. The latter ranges from the styles of walking, dressing, the rules of engagement with others, such as touching, distance, times of being somewhere, all the way to the entire social architectonic, including architecture. After all, the buildings are designed for movement, spaces, family, offices, monuments to royals, huge enterprises, all suggesting where, when and who one is in direct relationship to where others live and are. Our bodies, as Maurice Merleau-Ponty (2014) argued, are the very structure of our architectural surroundings. We do not know our world "in reality" from physics or physiology, but from our interaction, coextension with the world which we constantly build.

\section{References}

Althusser, L. (2005). For Marx. London: Verso.

Aristotle. (2008). Physics. Series: Oxford World's Classics. Oxford, New York: Oxford University Press. Baudrillard, J. (1983). Simulations. New York: Semiotext[e].

Descartes, R. (1985). The philosophical writings of Descartes. Vol. I. Cambridge: Cambridge University Press.

Dostoevsky, F. (2002). The brothers Karamazov. New York: Farrar, Straus and Giroux.

Habermas, J. (1968). Erkenntniss und Interesse. Frankfurt am Main: Suhrkamp.

Heidegger, M. (1962). Being and time. New York: Harper \& Row, Publishers, Incorporated.

Lyotard, J.-F. (1984). The postmodern condition: a report on knowledge. Series: Theory and History of Literature. Vol. 10. Minneapolis: University of Minnesota Press. 
Mann, Th. (1995). The magic mountain. New York: Alfred A. Knopf, Inc.

Merleau-Ponty, M. (2014). Phenomenology of perception. London and New York: Routledge.

Newton, I. (2010). The Principia: mathematical principles of natural philosophy. New York: Snowball Publishing.

Nietzsche, F. (1974). The gay science with a prelude in rhymes and an appendix of songs. New York: Vintage Books.

Planck, M. (1969). Treatise on thermodynamics. New York: Dover Publications, Inc.

Plato. (2010). Dialogues of Plato. Series: Simon \& Schuster Enriched Classic. New York: Simon \& Schuster, Inc.

Sophocles. (2008). Electra. Series: Cambridge Translations from Greek Drama. Cambridge: Cambridge University Press.

The Bhagavad Gita. (2007). Series: A Classic of Indian Spirituality. Tomales, CA: Nilgiri Press.

Tolstoy, L. (1994). Anna Karenina. New York: Random House, Inc.

\title{
POLICENTRINÉ KŪRYBINĖ KOMUNIKACIJA: DISPOZITYVUMAS
}

Algis MICKŪNAS

\begin{abstract}
Santrauka
Straipsnyje gvildenamas policentrinis potyris kaip kūrybos komunikacijos pagrindas su bet kuo, bet kada ir tuo lygmeniu, kuriuo bet kokia komunikacija suprantama kaip prasmé, kurianti kokị nors procesą. Dèl to tampa pasiekiami „Kiti“ iš kitų laikų, aprašomų tekstuose, atveriančiuose komunikaciją per lingvistines ir kultūrines medijas. Skaitome Platono tekstus ir ginčijamès su juo teisingumo klausimu arba diskutuojame apie visatos pradžią su astronomais. Šie du lygmenys - policentrinis ir dialoginis - papildomi konkrečiais tyrinejjimais, skirtais kūnui kaip aktyviai ir interaktyviai dimensijai, susietai su daugybe šiuolaikinių techninių medijų - pradedant filmais, televizija, internetu ir baigiant išmaniaisiais telefonais.
\end{abstract}

Reikšminiai žodžiai: komunikacija, kūrybiškumas, medijos, kūniškumas, interaktyvumas, Kiti. 